\title{
Türkiye'deki Astro-Jeodezik uygulamalar için sayısal zenit kamera sistemi**
}

\author{
Kerem Halıcıoğlu ${ }^{1,2,}$, Rasim Deniz ${ }^{2}$, Haluk Özener ${ }^{1}$ \\ ${ }^{1}$ Boğaziçi Üniversitesi Kandilli Rasathanesi ve Deprem Araştırma Enstitüsü, Jeodezi Anabilim Dalı, Istanbul, Türkiye \\ 2 İstanbul Teknik Üniversitesi, Geomatik Mühendisliği Bölümü, Istanbul, Türkiye \\ Özet
}

Jeodezi ve Jeofizik alanlarında yerin gravite alanının belirlenmesi ile ilgili pek çok güncel çalışma bulunmaktadır. Potansiyeli, ortalama deniz yüzeyi potansiyeline yakın olan jeopotansiyel yüzey "geoit", bir düşey datum olarak yükseklik sistemlerinin temelini oluşturur ve bu nedenle, koordinat transformasyonu,

Cilt: 1

Sayı: 2

Sayfa: $149-154$

Kasım 2012 ölcullerin indirgenmesi, yoğunluk arastırmaları ve benzeri çalısmalarda özel bir öneme sahiptir. Bir santimetre geoidinin belirlenmesi ile ilgili çalışmalar devam etmektedir. Bir cm-geoidi GNSS'den (Türkiye için TUSAGA-Aktif) rasyonel yararlanmanın temel koşuludur. Bu çalışmada güncel astro-jeodezik gözlemlere ilişkin Avrupa genelinde devam eden çalışmalara yer verilmiştir. Bu çalışma ayrıca veri elde etme, ölçme ekipmanları ve değerlendirme yöntemleri ile gözlem esasları ve Jeodezik Astronomide yeni teknolojiler ile ilgili gelişmeleri içermektedir. Bu çalışmanin son kısmında ise İstanbul'da tasarlanan ve ilk test gözlemleri gerçekleştirilen Sayısal Zenit Kamera Sistemi tanıtılmaktadır.

Anahtar Sözcükler

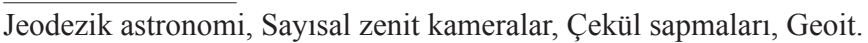

\section{Abstract \\ Digital zenith camera system for Astro-Geodetic applications in Turkey}

Pub. Online: 12 March 2013 There are several current investigations on gravity field of the earth in Geodesy and Geophysics. Earth sciences and space researches are also interested in gravity studies. Geoid, which approximately has an equal potential to the potential of mean sea level, is the main datum for height systems and is used for coordinate transformation, reduction of measurements, subsurface density variations and similar scientific studies. Current studies focus on the determination of cm level geoid, in order to use Global Navigation Satellite Systems (GNSS) such as Continuously Operating Reference Stations (CORS-TR/TUSAGA-Active) in Turkey effectively. This study introduces general information about recent astro-geodetic observations performed by different institutions all over Europe. Furthermore, it also gives some details about data acquisition, instrumentation and processing technique that focuses on observation principle and new technologies used in modern Geodetic Astronomy. Finally, this study introduces the system design and the first observations of a Digital Zenith Camera System (DZCS) used in Istanbul, Turkey.

Keywords

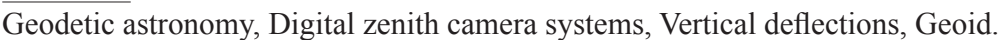

\footnotetext{
** Hakemli değerlendirme sürecinden geçerek, Jeodezi ve Jeoinformasyon Dergisi'nde yayına kabul edilen ve asıl yazı dili İngilizce olan "Digital zenith camera system for Astro-Geodetic applications in Turkey" başlıklı eserin Türkçe diline çevirisidir. Çeviren; Kerem Halıcıoğlu.
}

*Sorumlu Yazar: Tel: +90 (216) 5163265 Fax: +90 (216) 3320241

E-posta: kerem.halicioglu@boun.edu.tr (Halıcıoğlu K.), denizr@itu.edu.tr (Deniz R.), ozener@boun.edu.tr (Özener H.) 


\section{Giriş}

Geoit belirleme çalışmaları, gravimetrik (Stokes eşitliği ve gravite anomalileriyle), astro-jeodezik (astronomik ve jeodezik koordinatların yardımıyla elde edilen çekül sapmalarıyla), GPS/Nivelman (nivelman ile elde edilen ortometrik yükseklikler ve GPS ile elde edilen elipsoidal yükseklikler kullanılarak geoit ondülasyonlarının modellenmesi ile [ $N=h-H]$ ) ve küresel jeopotansiyel modeller (jeopotansiyel harmonik katsayıların belirlenmesi esasına dayanan yersel, uydu ve uzay teknikleri ile) gibi teorik ve gözlemsel yöntemler kullanır. Geoit modelleme sonuçlarının doğruluğu ve güvenilirliği farklı geoit belirleme yöntemlerinin karşılaştırılması ile sınanabilir. Farklı tekniklerin kombine edilmesi ile geoit belirlemede karşılaşılan kısıtlamalar ve sakıncalar elimine edilebilir.

GPS Nivelmanı en maliyetli geoit belirleme yöntemi iken gravimetrik yöntem topoğrafyayı karakterize eden yüksek yoğunluklu modelleme noktalarına gereksinim duyar. Gravimetrik yöntem kıyı çizgileri ve ülke sınırları için yeterli doğruluğu sağlayamamaktadır. Ayrıca deniz kıyıları yakınlarında ve göllerde doğrulukları sınırlıdır. Elde edilen sonuçlar, astro-jeodezik yöntemlerin gravimetrik yöntemlere göre 2-5 kat daha az maliyetli olduğunu göstermektedir (Gerstbach 1996). Astro-jeodezik çekül sapmaları çoğunlukla yerel ve bölgesel kitle dağılımının etkilerini içerir, bundan dolayı geoidin orta dalga kısmının belirlenmesi için önemli girdiler sağlarlar (Gerstbach 1996; Hirt ve Bürki 2006; Halicioglu vd. 2008).

Geleneksel optik-mekanik doğrultu ölçme sistemleri ve zaman belirleme aletleri ile elde edilen çekül sapmalarının doğruluğu \pm 1 " civarındadır. Son on yılda geliştirilen Sayısal Zenit Kamera Sistemleri (SZKS), CCD teknolojisi, GPS donanımları ve elektronik eğimölçerlerle ile donatılmıştır. Otomatikleştirilmiş kontrol ve değerlendirme prosedürleri çekül saplarının belirlenmesindeki doğruluğu $\pm 0.2^{\prime \prime}(2 \mathrm{~mm} / \mathrm{km})$ değerine kadar yükselmiştir. Almanya ve İsviçre'de SZKS ile gerçekleştirilen ilk çalışmaların ardından Avustralyalı araştırmacilar tarafindan Astro-Jeodezik Teknoloji Projesi kapsamında yürütülen çalışmalar bulunmaktadır (Hirt vd. 2010).

Ülkemizde gerçekleştirilen ulusal nirengi ağının oluşturulması çalışmaları kapsamında, 1976 yılında 98 noktada belirlenen astro-jeodezik çekül sapmaları kullanılmıştır (Şekil 1). Türkiye Astro-jeodezik Geoidi (TAG-94) ise 1994 y1lında 200 noktada belirlenen astro-jeodezik çekül sapmaları kullanılarak hesaplanmıştır (Ayhan ve Alp 1995). TAG-94'ün ardından geleneksel astro-jeodezik yöntemdeki doğruluk sınır-

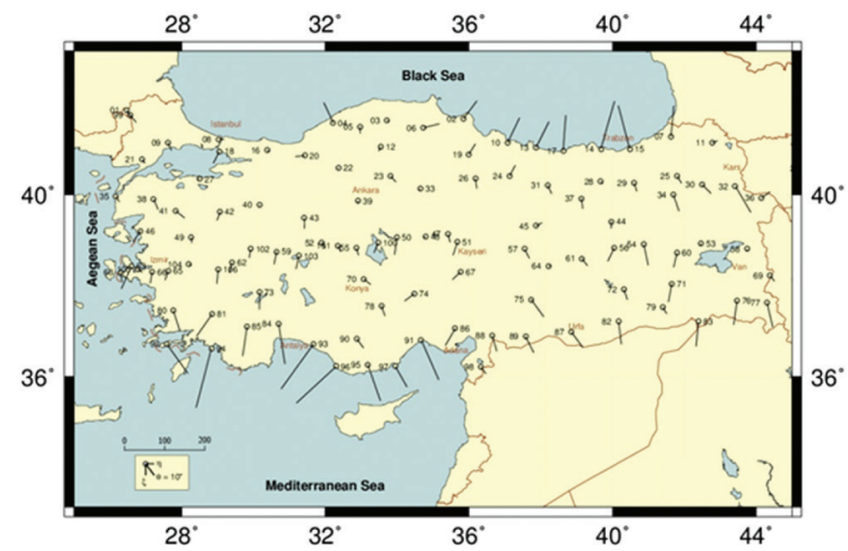

Şekil 1: Astro-jeodezik çekül sapmaları (Ayan 1976) lamaları nedeniyle çalışmalar yavaşlamıştır. Astro-jeodezik yöntem kullanılarak belirlenebilecek bir cm-geoidi için 1000 $\mathrm{km}^{2}$ büyüklüğünde bir alan için 5-10 noktanın yeterli olacağ belirtilmektedir (Gerstbach 1996).

\section{Gözlem esasları}

Jeodezik Astronomi’nin amaçlarından biri de, yıldızlara gerçekleştirilen gözlemlerle astronomik enlem $\Phi$, boylam $\Lambda$ ve azimutun $A$ belirlenmesidir (Şekil 2).

Astronomik enlem $\Phi$ ve astronomik boylam $\Lambda$, çekül çizgisinin teğetinin doğrultusu belirlerken, jeodezik koordinatlar $(\phi, \lambda)$ elipsoit normalinin doğrultusunu tanımlar. Bir noktada bu iki doğrultu arasındaki fark ise çekül sapması olarak adlandırılır (Şekil 3).

Jeodezik Astronominin bir diğer amacı da astronomik azimutların belirlenmesidir. Astronomik azimut, astronomik ufuktan (çekül çizgisinin teğetine dik düzlem) çekül çizgisinin teğetini ve hedef noktayı içeren astronomik meridyen düzleminin kuzey parçasından doğuya doğru ölçülen açı olarak tanımlanır (Jekeli 2012).

\subsection{CCD teknolojisi ve zenit kameralar}

CCD (Charged Coupled Devices) dedektörlerinin 1970'li yıllarda icadının ardından astronomi ve astrometride büyük bir gelişme sağlanmıștır. Jeodezik Astronomi de, optik ve analog ekipmanlarını CCD'ler ile yenileyerek bu değişimden etkilenmiştir. CCD dedektörlerin geleneksel fotoğrafik ve görsel yöntemlere göre pek çok üstünlüğü bulunmaktadır. CCD'ler yüksek duyarlılıkta algılayıcılar içerdiğinden gözlem sürelerini kısaltmaktadırlar. Ayrıca sayısal veri ürettiklerinden otomatik veri akışına uygundurlar.

Bir sayısal görüntü matris formunda kolon ve satırlarda konumlanmış piksellerden oluşur. Pikselin konumu belirli satır ve sütunu ifade eden iki boyutlu koordinatlarla ifade edilir. Bir CCD kamera, 1şığa duyarlı foto diyotlardan oluşan ve fotonları elektrik gerilimine çeviren bir algılayıcı kullanarak görüntüdeki bilgiyi kaydeder. Algılayıcı, piksellerin belirli bir sayıda bir dizi şeklinde sıralandığı satır ve sütunlardan oluşur. Bu çalışmada tasarlanan sistem, 2184x1472 pikselden oluşan $14.8 \times 10.0$ mm boyutlarında, Apogee Alta U32 CCD kamera bünyesinde bulunan Kodak KAF-3200ME algılayıcı kullanmaktadır. Yonganın bir pikseli ise $6.8 \times 6.8$ $\mu \mathrm{m}$ boyutlarındadır. Sistemin bu yonga ile gök küre üzerinde görüntüleyebildiği pencerenin boyutları $(\mathrm{FoV}), 20 \mathrm{~cm}$ çapında aynaya sahip bir teleskop ile birlikte kullanıldığında $25.5 \times 17.2$ yay dakikasına karşılık gelmektedir. Görüntülenen alandaki cisimlerin resim koordinatlarının elde edilebilmesi için görüntünün tanımlanması ve orta noktasının koordinatlarının belirlenmesi gerekmektedir. Bu işleme image extraction denilmektedir. Görüntüdeki yıldızlar benzer özelliklere sahip bir grup piksel olarak kabul edilmekte ve arka alandan grilik değerleri ile ayrılmaktadır. Yıldız merkezlerinin belirlenmesi işleminde doğrulukları 0.1-0.2 piksele ulaşan pek çok image extraction algoritması bulunmaktadır.

Image extraction işleminin ardından görüntülenen yıldızlar tanımlanmalı ve yıldız kataloglarında verilen Uluslararası Gök Koordinat Sistemi’ndeki (ICCS) koordinatları ile ilişkilendirilmelidirler. Günümüzde Guide Star Catalog (GSC), 


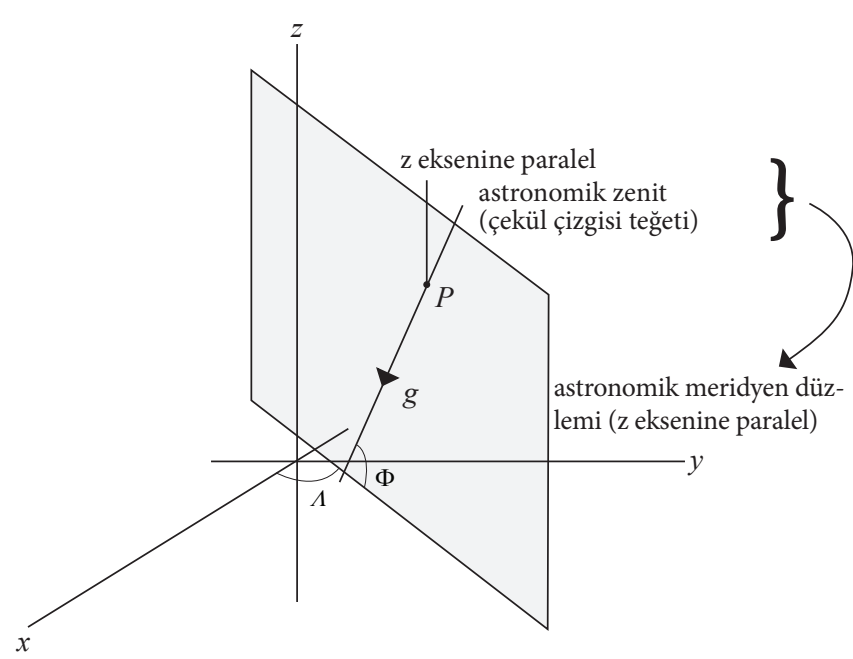

Şekil 2: Astronomik koordinatlar (Jekeli 2012)

TYCHO-2, ve USNO CCD Astrograph Catalog (UCAC) gibi yüksek doğruluk ve yoğunlukta yıldız katalogları yayınlanmaktadır. Bu çalışmada elde edilen görüntülerdeki referans yıldızların koordinatlarının belirlenmesinde UCAC2 ve UCAC4 katalogları kullanılmıştır. Amerika Birleşik Devletleri Deniz Kuvvetleri Gözlemevi (USNO) 2011 y1lında UCAC4 yıldız kataloğunu yayımlamıs ve 113 milyon yıldıza ait bilgileri barındıran tamamlanmış versiyonunu 2012 yılının Haziran ayında dağıtmaya başlamıştır. UCAC4 yardımıyla parlak referans yıldızların (10 $10^{\mathrm{mag}}-14^{\mathrm{mag}}$ 'a kadar) konum bilgileri 0.02 yay saniyesi ve sınır parlaklık değeri $16^{\text {mag }}$ a kadar olanlarınki ise 0.1 yay saniyesi düzeyinde elde edilebilmektedir.

Sonuç olarak, günümüz astrometri uygulamaları CCD teknolojisinden, hem yeryüzünden hem de uzaydan yapılan gözlemlerde yoğun olarak yararlanmaktadır. CCD gözlemlerinin en temel sorunu kamera yöneltme elemanların belirlenmesidir.

Kamera ister yeryüzünde isterse uzay aracında konumlanmış olsun yöntemin esasları temelde değişmemektedir. Kameranın yöneliminin belirlenmesi için dönme açılarının, deklinasyonun $\delta_{0}$, rektesansiyonun $\alpha_{0}$ ve kamera eksenindeki dönüş açısının $\kappa_{0}$ belirlenmesi gerekir (Şekil 4). Bu süreçte klasik fotogrametrik teknikte izlenen prosedür izlenir (Seeber 2003).

\subsection{Astrometrik plaka indirgemesi}

Yıldız alanının görüntüsü küresel bir yüzeyin düzleme izdüşümüdür (Şekil 5). Refraksiyon ve distorsiyonların olmadığ ideal şartlar altında, teğet düzlem koordinatları $(\xi, \eta)$ bilinen kamera parametrelerinden $\alpha_{0}, \delta_{0}$ yararlanılarak ve rektesansiyon sistemindeki yıldız koordinatları $(\alpha, \delta)$ kullanılarak hesaplanabilir (Seeber 2003).

Astrometrik plaka indirgemesi ile teğet düzlem koordinatları $(\xi, \eta)$ ve resim koordinatları polinomlar aracılığıyla ilişkilendirilebilir.

\subsection{Gözlem yöntemi ve ölçme ekipmanı}

Yıldız katalogları, Uluslararası Göksel Referans Sisteminde (ICRS) yıldızlara ait rektesansiyon sistemindeki koordinatla-

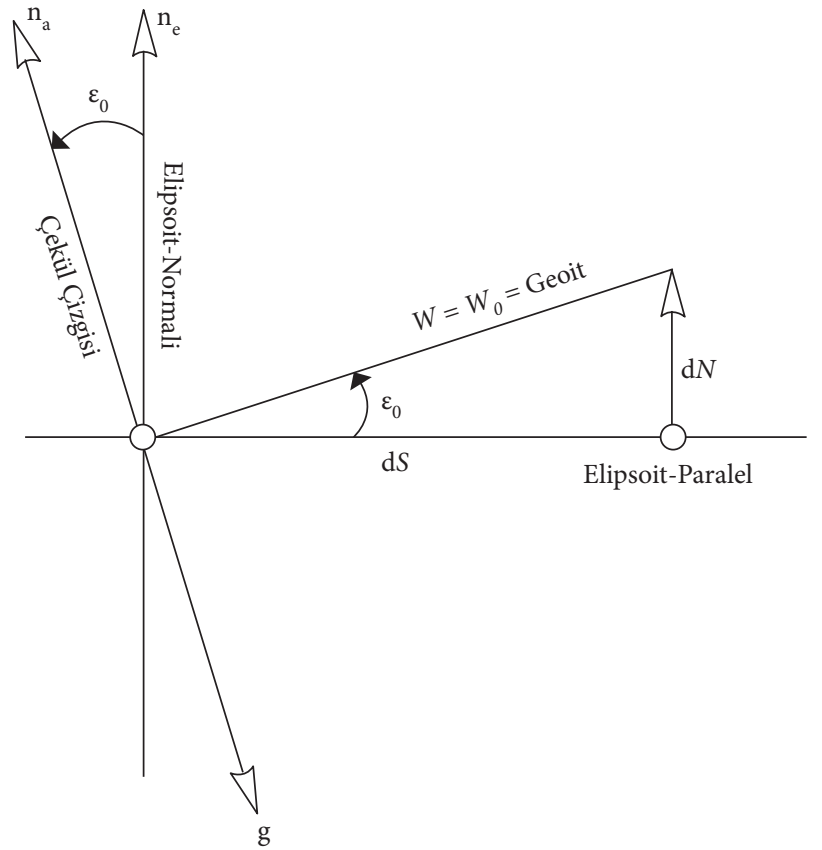

Şekil 3: Geoit yüksekliğinin değişimi ve çekül sapması arasındaki ilişki

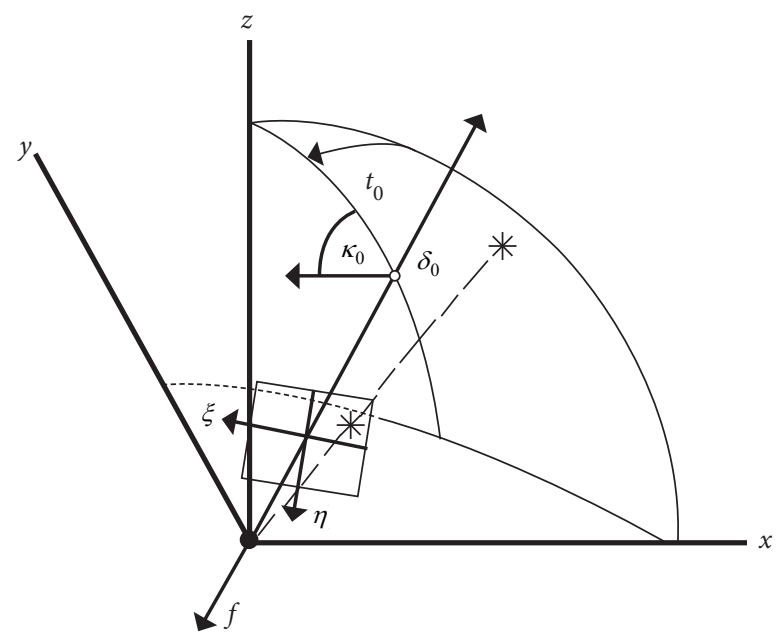

Şekil 4: Kamera yöneltme elemanları (Seeber 2003)

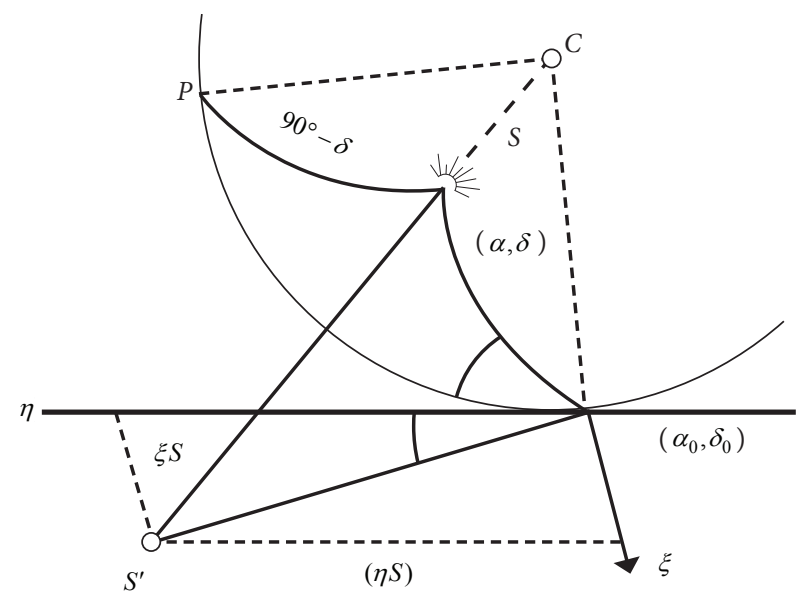

Şekil 5: Teğet düzlem koordinatları (Smart 1971) 
r1, deklinasyon $(\delta)$ ve rektesansiyonu $(\alpha)$ içerir. Yıldız kataloglarında yer alan konum bilgisini kullanabilmek için kameraya ait yaklaşık astronomik koordinatların $(\Phi, \Lambda)_{0}$ bilinmesi gerekir. SZKS gözlemlerinde GPS ile elde edilen jeodezik koordinatlar $(\varphi, \lambda)$ başlangıç için yaklaşık astronomik koordinatlar olarak kabul edilir.

Astronomik koordinatlar $(\Phi, \Lambda)$ yeryüzünde gözlem yapılan noktaların konumlarını tanımlarken, rektesansiyon sistemindeki koordinatlar yıldızların gökküre üzerindeki konumlarını ifade eder. Astronomik koordinatlar ve Rektesansiyon sistemindeki koordinatlar, tam olarak zenitte konumlanmış bir yıldız için Greenwich Görünen Yıldız Zamanı (GAST) ile ilişkilendirilebilir (Şekil 6).

$$
\Phi=\delta, \Lambda=\alpha-G A S T
$$

Ancak bir yıldız tam olarak zenit geçişindeyken gözlenemez, bu nedenle zenit ve civarındaki referans yıldızlar CCD kamera aracılığıyla görüntülenerek zenit doğrultusu referans yıldızların koordinatları yardımıyla hesaplanır. Zenit civarında görüntülenen yıldızların uygun kataloglar kullanılarak tanımlanması gerekmektedir.

Resim koordinat sisteminde tanımlanan koordinatlar $(x, y)$ Rektesansiyon sistemindeki koordinatlarla $(\alpha, \delta)$ doğrudan ilişkilendirilemezler. Ancak küre üzerinde tanımlanan koordinatların $(\alpha, \delta)$ ortak bir noktada $\left(\alpha_{0}, \delta_{0}\right)$ küreye teğet olan düzleme izdüşümünün tanımlanması gerekmektedir. Bu nedenle gnomik izdüşüm kullanılarak teğet düzlem koordinat$\operatorname{larının}(\xi, \eta)$ hesaplanması gerekir.

$\cot q=\cot \delta \cos \left(\alpha-\alpha_{0}\right)$

$\xi=\frac{\tan \left(\alpha-\alpha_{0}\right) \cos q}{\cos \left(q-\alpha_{0}\right)}$

$\eta=\tan \left(q-\delta_{0}\right)$

Teğet düzlem koordinatlarının ve resim koordinatlarının izdüşümsel dönüşüm ile ilişkilendirilmesi gerekir. Dönüşüm parametrelerin kestirilebilmesi için her iki sistemde tanımlanabilen en az dört yıldız gereklidir. Dört yıldızdan daha çok sayıda yıldızın tanımlanabildiği durumlarda ise dönüşüm parametreleri en küçük kareler yöntemi kullanılarak hesaplanır.

$\xi=\frac{A x+B y+C}{K x+L y+1}$

$\eta=\frac{D x+E y+F}{K x+L y+1}$

Zenit noktasının koordinatları iteratif bir işlemle enterpole edilir. Astronomik koordinatlar $(\Phi, \Lambda)$ ise Eşitlik 1 yard1miyla ve GAST kullanılarak hesaplanabilir.

İzdüşüm merkezinin doğrultusuna ait koordinatlar aşağ1daki formüller hesaplanabilir.

$$
\alpha_{z}=\alpha_{0}+\arctan \frac{\xi_{z}}{\cos \delta_{0}-\eta_{z} \sin \delta_{0}}
$$

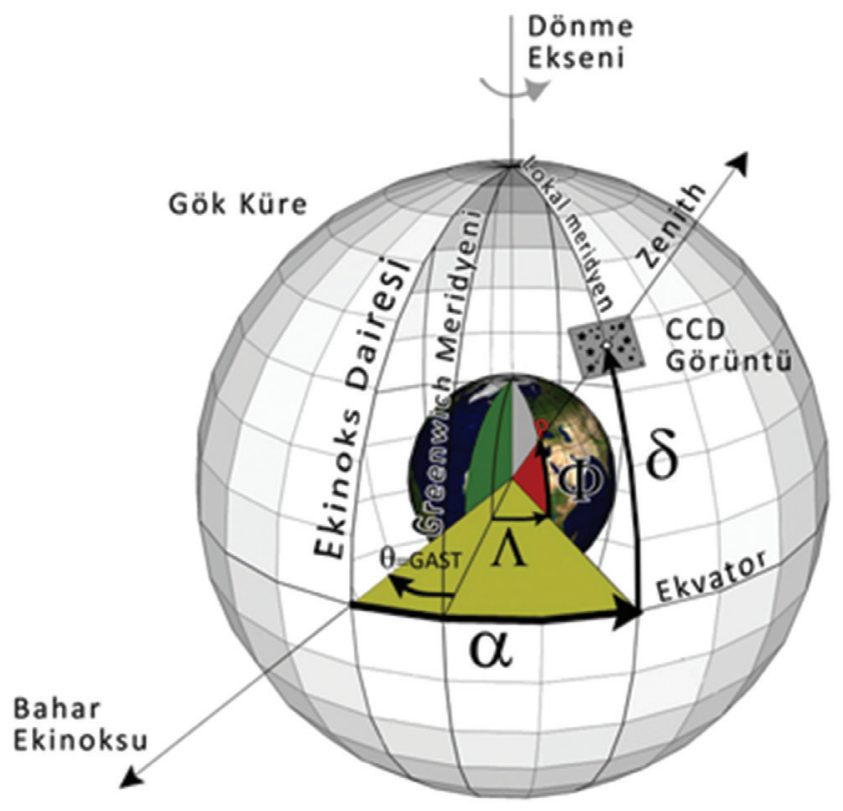

Şekil 6: SZKS temel prensibi (Hirt ve Bürki (2002)'den güncellenmiştir)

$\delta_{z}=\arctan \frac{\left(\eta_{z}+\tan \delta_{0}\right) \cos \left(\alpha-\alpha_{0}\right)}{1-\eta_{z} \tan \delta_{0}}$

Gerçekleştirilen bir kaç iterasyonun ardından koordinatlar arasındaki farklar bir kaç mili yay saniyesinin altına iner. Sonuç olarak çekül sapması bileşenleri $(\xi, \eta)$, astronomik $(\Phi, \Lambda)$ ve GPS ile elde edilen elipsoidal koordinatlar $(\varphi, \lambda)$ kullanılarak hesaplanır.

$\xi=\Phi-\varphi \quad, \quad \eta=(\Lambda-\lambda) \cos \varphi$

\section{Astro-jeodezik aletler}

GNSS'den etkin olarak yararlanabilmek için bir cm-geoidinin belirlenmesi çok önemlidir, bu nedenle güncel çalışmalar prezisyonlu geoit belirlemeye odaklanmıştır. Astro-jeodezik teknik en eski temel geoit belirleme yöntemlerinden birisidir. Ancak analog ekipmanlardaki ve zaman belirlemedeki kısıtlamalar bu yöntemin kullanımını azaltmıştır. Geçmişte gerçekleştirilmiş çalışmalar geleneksel optik-mekanik doğrultu ölçme ve zaman belirleme yöntemleri ile çekül sapmalarının \pm 1 " doğrulukla belirlenebildiğini göstermiştir.

Doğrulukları 0.5" değerine ulaşan ilk zenit kameralar olan TZK1 ve TZK2, 1970'li y1llarda Almanya'da (Gessler 1975) tasarlanarak kullanılmaya başlamıştır. Daha sonra Hannover Jeodezi Enstitüsü (IfE Hannover) ve ETH Zürih Jeodezi ve Jeodinamik Laboratuvarının (ETH GGL) işbirliği ile bu sistemler modern ekipmanlarla donatılmıştır (Şekil 7). Bu kameralar ile özellikle dağlık alanlarda astro-jeodezik çekül sapmalarının belirlenmesi amaçlanmıştır. İlk zenit kameralar fotoğraf plakaları gibi analog algılayıcılar ve kronograf gibi geleneksel zaman belirleme yöntemlerini kullanmaktaydılar. Geliştirilen bu sistemle oldukça başarılı olsalar da elde edilen görüntülerin değerlendirilmesinde güçlük çekiliyordu. Ancak yine de analog zenit kameralar 1975-1984 y1lları arasında çok sayıda astro-jeodezik çalışmada kullanılmıştır. 

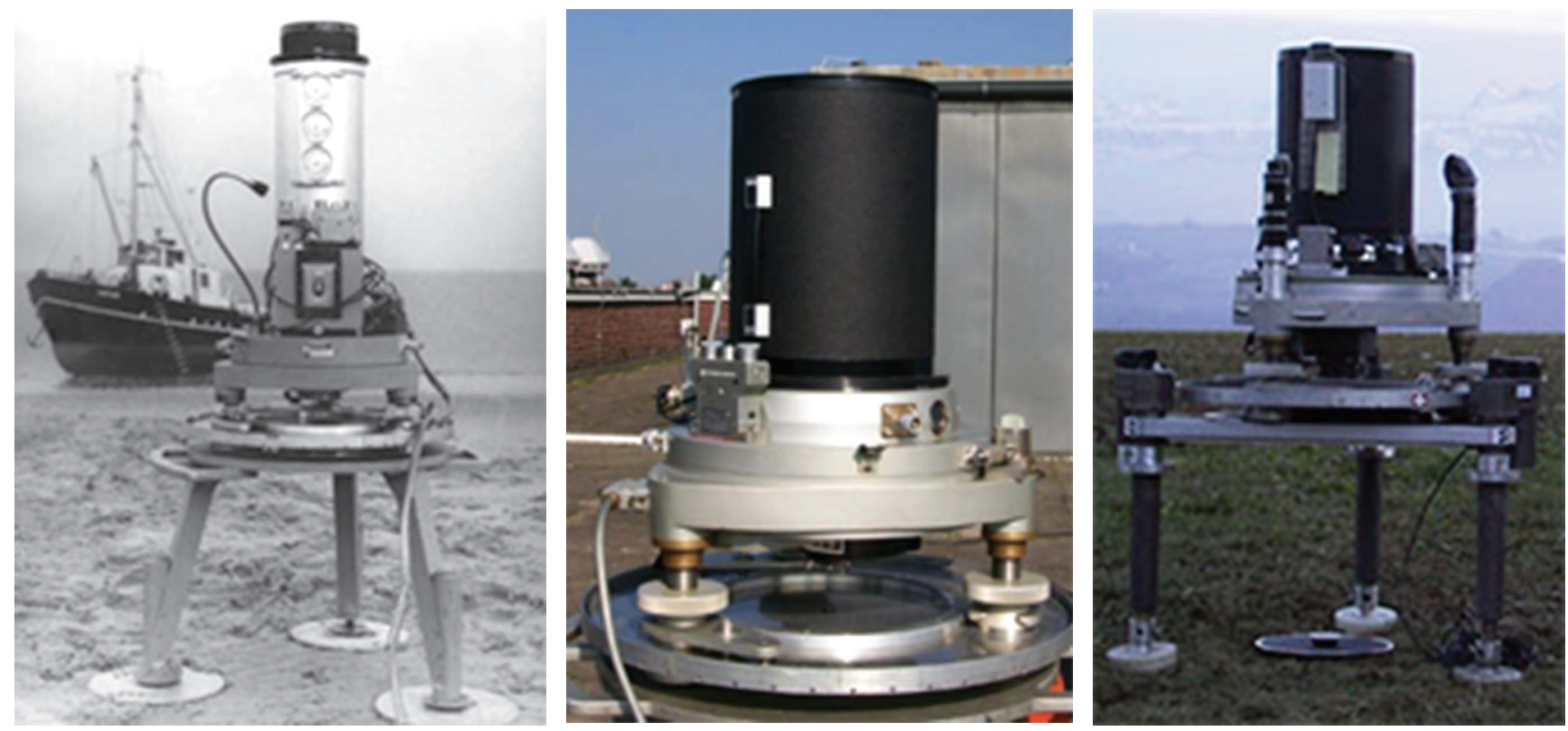

Şekil 7: Analog ve Sayısal Zenit Kameralar (Gessler 1975; Hirt ve Burki 2006)

CCD aygitlarının icadının ardından jeodezik astronomide devrim niteliğinde gelişmeler gerçekleşmiştir. Bunun üzerine analog zenit kameralar yeniden tasarlanarak CCD kameralar, GPS ve prezisyonlu eğim ölçerlerle donatılmıştır. IfE Hannover ve GGL ETH 2000'li yılların başından itibaren yüksek doğruluklu sayısal zenit kameralarını çalıştırmaya başlamışlardır. Geliştirilen bu sayısal zenit kamera sistemleri 2003 yılından itibaren Avrupa genelinde yerel ve bölgesel cm ve mm doğruluklarında geoitler belirleyebilmek için yaklaşık 900 yeni istasyonda çekül sapması verisi üretmiştir (Hirt vd. 2010).

Hannover (Almanya) ve ETH Zürih (İsviçre) Üniversiteleri, İsviçre (101 sayısal ve 433 analog gözlem), Kuzey Almanya ve Hollanda (175 gözlem), Harz dağları (120 gözlem), Bavyera Alpleri (182 gözlem), Portekiz (17 gözlem) ve Yunanistan (28 gözlem) gibi Avrupa ülkelerinde pek çok astro-jeodezik gözlem gerçekleştirmiştir. Analog gözlemlerin doğrulukları 0.3-0.5 yay saniyesi arasında bildirilirken, say1sal zenit kameraların doğrulukları 0.1 yay saniyesi olarak rapor edilmektedir (Hirt ve Sebeer 2008). Hirt vd. (2010), elde edilen 1056 gözlemi EGM2008 yer gravitasyonel modelini değerlendirmek ve astro-jeodezik veri ile uyumluluğunu tartışmak için kullanmıştır. Bir diğer SZKS çalışması 2011 yılında Amerika Birleşik Devletlerinde gerçekleştirilmiştir. Texas eyaletinde belirlenen $330 \mathrm{~km}$ uzunluğunda bir profil boyunca geoit eğiminin belirlenmesi amacıyla sürdürülen Geoid Slope Validation Survey isimli proje kapsamında 228 istasyonda çekül sapmaları belirlenmiş ve bu gözlemlerin doğruluğu 0.10.05 yay saniyesi olarak rapor edilmiştir (Smith vd. 2011).

Almanya ve İsviçre'de gerçekleştirilen bu öncü çalışmalar ve yüksek prezisyonlu bir astro-jeodezik geoidin belirlenme gereksinimi bizim çalışmamızı olduğu kadar Polonya (Kudrys 2009) ve Sirbistan'daki (Ogrizovic 2009) diğer çalışmaları da motive etmiştir. Ülkemizde gerçekleştirilen Sayısal Zenit Kamera Sistemi ile ilgili çalışma İstanbul Teknik Üniversitesi ve Boğaziçi Üniversitesi işbirliği ile TÜBİTAK tarafından desteklenerek sürdürülmektedir.

\section{Sistem tasarımı ve test gözlemleri}

Geçtiğimiz bir yılda İstanbul ve Antalya'da farklı donanım konfigürasyonları kullanılarak pek çok test gözlemi gerçekleştirilmiştir (Halicioglu vd. 2011; Halicioglu vd. 2012). Bu test gözlemleri sırasında $35 \mathrm{~cm}$ açıklığa sahip SchmidtCassagrain tipi bir teleskop, eğim ölçerler, çift frekanslı GPS alıcısı ve sistemin kontrolü ile verilerin değerlendirilmesi için kullanılan bir kontrol ünitesi kullanılmıştır.

Farklı sistem bileşenlerinin testlerinin ardından, $20 \mathrm{~cm}$ açıklıklı bir Meade LX200GPS teleskop, Leica Nivel 210 eğim sensörleri, Apogee Alta U32 CCD Kamera ve GPS donanımlarının uygun olduğuna karar verilmiştir (Şekil 8).

Test gözlemleri Kandilli Rasathanesi ve Deprem Araştırma Enstitüsünde bu çalışma için özel olarak yeniden tasarlanan Zenit Kamera gözlemevinde gerçekleştirilmiştir (Şekil 9).

\section{Sonuçlar}

Türkiye Ulusal Jeodezi Komisyonunun tartışmaya açtığı ve 1-cm doğruluğunda Türkiye geoidi hedefleyen Türkiye Ulusal Yükseklik Sisteminin Modernizasyonu projesi son günlerde ülke gündeminde yer almaktadır. Bu bağlamda yeni, tutarlı ve prezisyonlu yüzey gravite gözlemleri, havadan gravite ölçmeleri, düşey hız alanı ve nivelman ağındaki deformasyonlar, daha fazla sayıda ve stabil GPS/Nivelman istasyonlarının tesisi, topoğrafik yoğunluk modeli ve sayısal arazi modelleri gibi konuların tartışıldığı bir süreç işletilmektedir (TNUGG 2011). Yüksek prezisyonlu bir geoit modeline ulaşabilmek için homojen veri üretilebilen, yukarıda da bahsedilen çeşitli tekniklerin yanında astro-jeodezik yöntemin de tartışmalara dahil edilmesi gerekmektedir. Unutulmamalıdır ki ölçmelerdeki veri eksiklikleri ya da boşluklar modelleme süreçlerinde sorunlar yaratmaktadır. İsviçre geoit modeli örneğinde olduğu gibi Avrupa'da yüksek prezisyonlu geoit modellerinin elde edilmesi konusunda başarı sağlanmıştır. İsviçre' de 2000'li yılların başından itibaren geoit belirleme çalışmalarında, astro-jeodezik yöntemi de içeren farklı yöntemlerin kombinasyonları kullanılmıştır. EUREF 2004 yılı raporlarına göre, tüm yöntemlerin değerlen- 


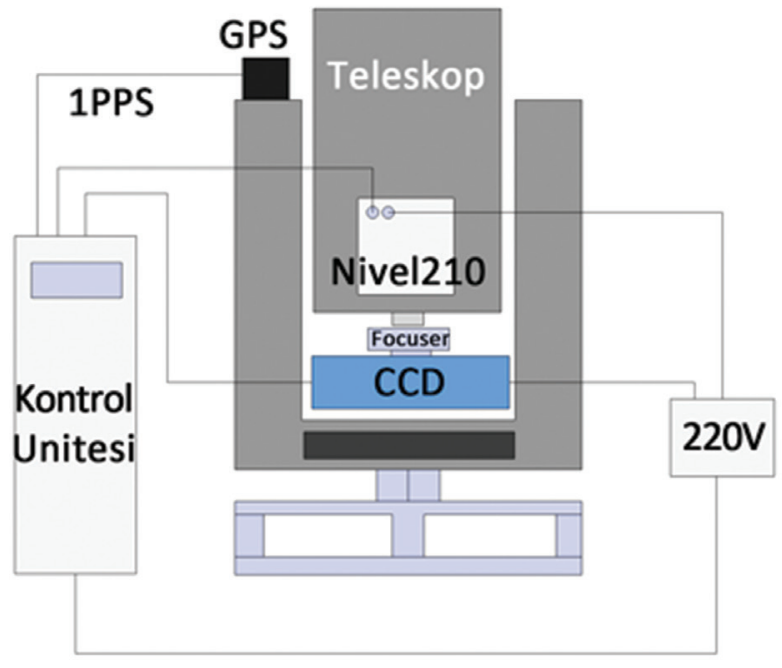

Şekil 8: Bu çalışmada kullanılan Zenit Kameranın tasarım şeması

dirmeye alınarak hesaplandığı İsviçre geoidinin doğruluğu 1-3 $\mathrm{cm}$ civarındadır. Farklı ülkelerde gerçekleştirilen çalışmalar astro-jeodezik çözümler ile gravimetrik çözümler arasındaki farklılıkların yalnızca bir kaç cm civarında olduğunu göstermektedir (Marti 2004). Gravite verisinin, özellikle ülkenin kuzey ve güney sahilleri boyunca uzanan dağlık alanlarda gözlem yapılamamasından kaynaklanan düzensizlikleri, geoit modellemede sorunlara neden olmaktadır. Dağlık alanlarda ve kıyı bölgelerinde astro-jeodezik ya da gravimetrik verinin çalışmalara dahil edilmesi gerekmektedir. Ulusal modellerin geliştirilmesi için SZKS kullanılarak astro-jeodezik verinin elde edilmesi ve geoidin orta dalga etkilerinin belirlenmesi mümkündür. $\mathrm{Bu}$ bağlamda, SZKS ile çekül sapmalarının elde edilmesi üzerine yoğunlaşan bu çalışmanın ülkemizdeki yükseklik modernizasyonu çalışmalarına katkı sağlayacağı düşünülmektedir.

\section{Teşekkür}

Bu çalışma TÜBİTAK tarafından 111Y125 numaralı proje kapsamında Ocak 2012 tarihinden itibaren desteklenmektedir.

\section{Kaynaklar}

Ayan T., (1976), Astrogeodatische Geoidberechnung für das Gebiet der Türkei, Doktora Tezi, Geodätisches Institut der Universität Fridericiana Karlsruhe, Almanya.

Ayhan M.E., Alp O., (1995), Türkiye Astro-jeodezik Jeoidi-1994 (TAG-94). Türk Haritacılığının 100. yılı TUJJB ve TUFUAB Kongresi Bildiriler Kitab1, Ankara, Türkiye, 307-320 ss.

Gerstbach G., (1996), How to get an European centimeter geoid ("astro-geological geoid"), Physics and Chemistry of the Earth, 21(4), 343-346.

Gessler J., (1975), Entwicklung und Erprobung einer transportablen Zenitkamera für astronomisch-geodätische Ortsbestimmungen. Wiss. Arb. Lehrst. für Geod., Phot. und Kart. Techn. Univ. Hannover Nr. 60, Almanya.

Halicioglu K., Ozener H., Deniz R., (2008), Current Geoid Studies in Turkey and the need for Local High-Precision Astrogeodetic Geoid Determination Using CCD/Zenith Cameras, American Geophysical Union, Fall Meeting 2008, San Francisco, CA, ABD

Halicioglu K., Deniz R., Ozener H., (2011), Astro-geodetic Measurements using Digital Zenith Camera System in IstanbulTurkey, EGU General Assembly Viyana, Avusturya

Halicioglu K., Deniz R., Ozener H., (2012), Determination of AstroGeodetic Vertical Deflections using Digital Zenith Camera System in Istanbul, Proceedings FIG International Congress 2012, Roma, İtalya.

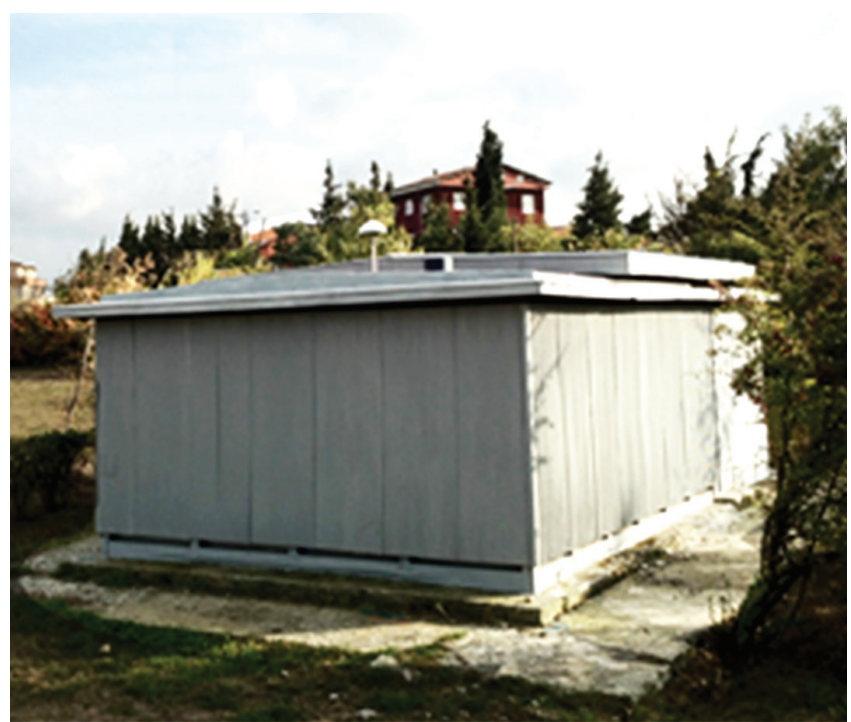

Şekil 9: Zenit Kamera Test Istasyonu

Hirt C., Bürki B., (2002), The Digital Zenith Camera - A New HighPrecision and Economic Astrogeodetic Observation System for Real-Time Measurement of Deflections of the Vertical, Proceeding of the 3rd Meeting of the International Gravity and Geoid Commission of the International Association of Geodesy, Selanik, Yunanistan.

Hirt C., Bürki, B., (2006), Status of geodetic astronomy at the beginning of the 21st century, Festschrift Univ.- Prof. Dr.-Ing. Prof. h.c. Günter Seeber anlässlich seines 65. Geburtstages und der Verabschiedung in den Ruhestand (Hirt C., Ed.), Wissenschaftliche Arbeiten der Fachrichtung Geodäsie und Geoinformatik an der Universität Hannover, Nr. 258, ss.81-99.

Hirt C., Seeber G., (2008), Accuracy Analysis of vertical deflection data observed

with the Hannover Digital Zenith Camera System TZK2-D. Journal of Geodesy, 82(6), 347-356, DOI: 10.1007/s00190-007-0184-7

Hirt C., Bürki B., Guillaume S., Featherstone W., (2010), Digital Zenith Cameras - State-of-the-Art Astrogeodetic Technology for Australian Geodesy, Proceedings FIG International Congress 2010, Sydney, Avusturalya.

Jekeli C., (2012), Geometric Reference Systems in Geodesy, Ohio State University, Ohio, USA, 209ss.

Marti U., (2004). High Precision combined geoid determination in Switzerland, Proceedings IAG GGSM2004 Symposium, Porto, Portekiz.

Kudrys J. (2009), Automatic Determination of the Deflections of the Vertical - First Scientific Results, Acta Geodynamics et Geomaterialia 6(3), 233-238.

Ogrizovic V. (2009), A Construction of an Advanced Measuring System for Astro-geodetic Determinations, Publ. Astron. Obs., Belgrade No. 86, 145-150.

Seeber G., (2003), Satellite Geodesy, Walter de Gruyter, 2. bs., Berlin, Almanya, 589ss.

Smart W.M., (1971), Textbook on Spherical Astronomy, Cambridge University Press, Cambridge, Büyük Britanya, 430ss.

Smith D., Holmes S., Li X., Wang Y., Archer-Shee M., Singh A., Middleton C., Winester D., Roman D., Bürki B., Guillaume S., (2011), Initial Results of the Geoid Slope Validation Survey of 2011, American Geophysical Union Fall Meeting 2011 San Francisco, CA, ABD

TNUGG, (2011), Turkish National Union of Geodesy and Geophysics National Reports of Geodesy Commission of Turkey for 2007-2011, http://www.iag-aig.org/ attach/5015ba0f03bf732e 1543f4120f15ec9a/turkey.pdf, [Erişim 12 Ekim 2012] 